C. Meisinger ${ }^{1,2}$
A. Döring
M. Heier
B. Thorand
H. Löwel ${ }^{1,2}$
for the MONICA/KORA Study Group

\author{
Typ-2-Diabetes in Augsburg - ein epidemiologischer Überblick
}

\section{Type 2 Diabetes Mellitus in Augsburg - an Epidemiological Overview}

\section{Zusammenfassung}

Der vorliegende Artikel gibt eine Übersicht über die Diabetesprävalenz sowie die antidiabetische Therapie über einen Zeitraum von 17 Jahren. Die Risikofaktoren für die Krankheitsentstehung und die Auswirkungen des Diabetes auf die kardiovaskuläre Morbidität werden diskutiert. Außerdem werden Veränderungen im Lebensstil und Risikofaktorprofil bei Diabetikern aufgezeigt. Die Ergebnisse beruhen auf Daten der MONICA/KORAAugsburg-Surveys S1-S4, die zwischen 1984/85 und 1999/2001 in der Studienregion Augsburg, Süddeutschland, durchgeführt wurden, und des HI-Registers. Im Gegensatz zu den meisten Studien aus anderen Ländern war in der 25- bis 74-jährigen Augsburger Bevölkerung in den letzten Jahren keine Zunahme der Prävalenz des bekannten Diabetes zu verzeichnen. Adipositas und körperliche Inaktivität stellen die beiden Hauptrisikofaktoren für die Entstehung eines Typ-2-Diabetes dar. Weitere modifizierbare Risikofaktoren wie Rauchen und Hypertonie wurden in der Augsburger Bevölkerung mit der Entstehung eines Typ2-Diabetes in Verbindung gebracht. In Übereinstimmung mit den Empfehlungen einer intensivierten Blutzuckereinstellung hat sich während der Studienperiode die Diabetesbehandlung kontinuierlich verbessert. Dagegen lässt der als ungünstig zu bezeichnende Gesundheitszustand von Diabetikern in der Augsburger Bevölkerung vermuten, dass die Empfehlungen zur Primärprävention von kardiovaskulären Erkrankungen bei Diabetikern bis zum Jahr 1999/2001 nicht ausreichend in die Praxis
Abstract

This article provides an overview of the prevalence of type 2 diabetes and the antidiabetic treatment over a 17 year study period. The causes of the disease and the impact of diabetes on cardiovascular disease (CVD) morbidity are discussed. Furthermore, changes in lifestyle and risk factor profile in persons with diabetes are reported. We present data from the MONICA/KORA surveys S1-S4 conducted between1984/85 and 1999/2001 in the region of Augsburg, Southern Germany and the Augsburg Myocardial Infarction Registry. Contrary to most studies from other countries, in the 25 to 74 year old Augsburg population the prevalence of known diabetes did not increase over the last years. Obesity and decreased physical activity are the two main lifestyle related risk factors for type 2 diabetes. Recently, further modifiable risk factors such as smoking and hypertension have been associated with the development of type 2 diabetes in the Augsburg population. Consistent with recommendations to intensify glucose control in diabetic persons the diabetes treatment continuously improved during the study period. However, health status of persons with diabetes is far from optimal in the Augsburg population suggesting that recommendations for primary prevention of CVD in diabetic persons were not sufficiently put into practice until 1999/2001. Furthermore, data from the MONICA/KORA Augsburg Myocardial infarction registry underline the challenge that in particular men and women with diabetes should receive intensive preventive interventions proven

The MONICA/KORA study group consists of: KORA: H.-E. Wichmann (speaker), H. Löwel, C. Meisinger, T. Illig R. Holle, J. John and co-workers who are responsible for the design and conduct of the KORA studies; MONICA: U. Keil (principal investigator), A. Döring, B. Filipiak, H. W. Hense, H. Löwel, J. Stieber and co-workers who were responsible for the design and conduct of the MONICA studies.

affiliation

${ }^{1}$ Augsburg Central Hospital, MONICA/KORA Myocardial Infarction Registry, Augsburg, Germany ${ }^{2}$ GSF National Research Center for Environment and Health, Institute of Epidemiology, Neuherberg, Germany

correspondence

Dr. Christa Meisinger, MPH · Central Hospital of Augsburg, MONICA/KORA Myocardial Infarction Registry · Stenglinstraße 2 · 86156 Augsburg · Germany · E-mail: christa.meisinger@gsf.de DOI 10.1055/s-2005-858251 ISSN 0949-7013 
umgesetzt wurden. Zudem unterstreichen die Daten aus dem MONICA/KORA-Augsburg-Herzinfarktregister die Notwendigkeit, vor allem bei Personen mit Diabetes mellitus intensiviert präventive Maßnahmen, die nachweislich das kardiovaskuläre Risiko vermindern, zu ergreifen. Die Daten der MONICA/KORAAugsburg-Studien zeigen, dass der Diabetesprävention zukünftig ein hoher „public health“-Stellenwert zukommen sollte.

\section{Schlüisselwörter}

Diabetes mellitus · Epidemiologie · Trends · Prävalenz · Risikofaktoren to reduce CVD risk. In conclusion, data from the MONICA/KORA Augsburg studies suggest that it should become an important public health priority to prevent diabetes mellitus.

\section{Key words}

Diabetes mellitus · epidemiology $\cdot$ trends $\cdot$ prevalence $\cdot$ risk factors

\section{Introduction}

Type 2 diabetes constitutes a major health problem and substantially contributes to morbidity and mortality [1]. Long-standing diabetes is associated with severe complications, such as blindness, kidney failure, and lower-extremity amputation [2]. Besides these well-recognized microvascular complications, persons with diabetes also have an increased risk of macrovascular complications, including diseases of coronary arteries $[3,4]$, peripheral arteries [5], and carotid vessels [6]. Furthermore, cardiovascular complications remain the leading cause of death among patients with type 2 diabetes [7]. The epidemic of type 2 diabetes is still increasing, with a trend towards earlier age at onset. Interactions of genetic susceptibility and environmental factors are the likely cause [8]. Between 1995 and 2025 the prevalence of diabetes is projected to rise from 135 million to 300 million affected world-wide, with the most dramatic increase occurring in developing countries [9]. In the present review we focus on the prevalence of diabetes mellitus and on antidiabetic treatment in Augsburg over a 17 year study period. The causes of the disease and the impact of diabetes on cardiovascular disease morbidity are covered. Furthermore, changes in lifestyle and risk factor profile in persons with diabetes over the last two decades are reported. We incorporate data from three populationbased MONICA (Monitoring of Trends and Determinants in Cardiovascular Disease) surveys and one KORA (Kooperative Gesundheitsforschung in der Region Augsburg) survey conducted between1984/85 and 1999/2001 in the region of Augsburg, Southern Germany. Furthermore, data from the MONICA/ KORA Augsburg myocardial infarction registry is presented.

\section{Methods}

\section{Study population}

Three independent cross-sectional surveys were carried out in 1984/85 (S1), 1989/90 (S2) and 1994/95 (S3) to estimate the prevalence and distribution of cardiovascular risk factors among men and women living in the study region [10, 11]. From 1999 to 2001 the KORA Survey S4 (2000) was conducted in the same study region and with the same design as in the previous MONICA surveys. Independent samples were drawn for the different surveys. The age distribution ranged from 25 to 64 years in the survey 1984/85 and 25 to 74 years in the surveys 1989/90,1994/ 95 and 1999/2001 [12].
In all surveys, extensive baseline information was gathered. In addition all participants underwent a standardized medical examination including collection of a non-fasting blood sample. All measurement procedures have been described elsewhere in detail $[11,12]$. In the interview participants were asked, whether they suffer from diabetes and if the diagnosis was made by a physician. All subjects were also asked to provide details on their current antidiabetic medication. Previously known diabetes was defined based on self-reported physician diagnosis or use of antidiabetic agents. We could not distinguish between type 1 and type 2 diabetes mellitus. But, as type 2 diabetes mellitus constitutes approximately $90-95 \%$ of all cases of diabetes in the Western countries [9] it can be assumed that most of the persons who reported to have diabetes in this study suffer from type 2 diabetes. Therefore, in the present study the term type 2 diabetes is used.

In this review we also report results of prospective analyses using data of the KORA health questionnaire (GEFU1) in 1997/98.

Since diabetes mellitus was added to the risk factor profile of patients with acute myocardial infarctions (AMI) [13], data from the MONICA/KORA Augsburg myocardial infarction registry can show differences in prognosis after AMI between diabetic and non-diabetic patients.

\section{Results}

\section{Prevalence of diabetes}

Although it has been suggested that the prevalence of type 2 diabetes in Europeans is lower than in any non-European population [14], in the last years several European studies also have reported an increase in diabetes prevalence [15-17]. However, in Southern Germany the prevalence of known diabetes did not increase over 17 years in the 25 to 74 year old population [18]. In S1 the total prevalence was $2.7 \%$ for men aged 25 to 64 years and $2.0 \%$ for women of the same age. In S4 the prevalence was $2.5 \%$ for 25 to 64 year old men and $2.7 \%$ for women, respectively. The prevalence of diabetes increased with age in both sexes. In persons younger than 44 years the prevalence of diabetes was lower than $2 \%$ in both sexes during the whole observation period, whereas in 65 to 74 years old men and women the prevalence of diabetes was about $11 \%$. These results are very similar to the observations from the German National Health Interview and 
Examination Survey which also did not find an increase in the prevalence of known diabetes between 1991 and 1998 [19]. To analyse the reasons for the stable diabetes prevalence in the region of Augsburg over the 17 year study period, data on diabetes incidence, diagnosis of the disease, survival after diagnosis and general life expectancy have to be taken into account. The participation rate in the surveys decreased only slightly from S1 (79\%) to S3 (75\%). However, in S4 the participation rate was only $67 \%$. In that survey a short questionnaire was used in nonresponders. It was estimated that non-participants were about two times more likely to have diabetes mellitus. Therefore, in S4 the prevalence of known diabetes mellitus could have been underestimated to a greater extent and thus, a small increase in diabetes prevalence between S3 and S4 could have been masked.

To quantify the diabetes prevalence accurately, the number of undiagnosed cases has to be included. In S4 an oral glucose tolerance test (OGTT) was performed in 55 to 74 year old non-diabetic study participants. In this age-group the diabetes prevalence (known previously and unknown) was about $17 \%$ using diagnostic cut-points defined by the WHO and an additional $23 \%$ of this subset had impaired glucose tolerance or impaired fasting glucose. As a result, about the same number of previously undiagnosed cases with diabetes was found as disposed [20, 21]. In S1-S3 no OGTT was performed, therefore, no previous data are available concerning trends in undiagnosed diabetes. Efforts to screen individuals at risk for the development of diabetes are important because the risk of progression from impaired glucose tolerance to type 2 diabetes may be reduced by lifestyle changes, including weight loss and/or pharmacotherapy [22, 23]. Moreover, early diagnosis becomes even more critical in light of data indicating that the clock starts ticking for cardiovascular disease (CVD) complications of diabetes many years before the diagnosis of clinical type 2 diabetes [24].

\section{Causes and risk factors for type $\mathbf{2}$ diabetes}

The worldwide increase of type 2 diabetes over the past two decades has been fuelled by globalization, which has led to changes in lifestyle in both industrialized and developing countries. Environmental and lifestyle factors, mainly obesity and physical inactivity are important in inducing type 2 diabetes mellitus [14]. In the MONICA/KORA Augsburg Cohort Study based on 3052 men and 3114 women (aged 35 to 74 years) who participated in one of the three MONICA surveys the sex-specific incidence of type 2 diabetes mellitus was assessed. Between 1984 and 1998 in total 128 incident cases of diabetes were reported among men and 85 cases among women. The age-standardized incidence rate was 5.8/1000 person-years for men and 4.0/1000 person-years for women. In the MONICA/KORA Augsburg Cohort Study age, BMI, a parental history of diabetes, and low HDL cholesterol values were identified as independent risk factors for type 2 diabetes mellitus in men and women. Elevated systolic blood pressure, regular smoking and a high daily alcohol intake was associated with an increased risk for diabetes in men only. On the other hand, high uric acid values and physical inactivity during leisure time were predictors for type 2 diabetes in women only [25].
Time trends in the prevalence of lifestyle factors and cardiovascular risk factors in the diabetic population

The prevalence of cardiovascular risk factors is high among persons with type 2 diabetes (Table $\mathbf{1}$ ) and accounts for the increased CVD risk in diabetic persons. The prevalence of obesity and hypertension decreased among 25 to 64 year old diabetic men, but increased among diabetic men aged 65 to 74 years and diabetic women, respectively, between 1984/85 and 1999/2001 in Augsburg. Dyslipidemia decreased in younger and older men and women with diabetes during the study period. However, data from the S4 indicated, that the health status of diabetic persons is far from optimal: a high percentage of the 25 to 64 year old persons with diabetes was obese (men 36\%, women $72 \%$ ), had hypertension (men 56\%, women $73 \%$ ), and dyslipidemia (men $51 \%$, women $41 \%$ ) and a considerable proportion smoked cigarettes (men $24 \%$, women $14 \%$ ).

It seems that the recommendations for primary prevention of CVD in persons with diabetes through lifestyle changes such as smoking cessation, weight loss and increasing physical activity were not sufficiently put into practice until 1999/2001 [26, 27].

\section{Time trends in antidiabetic treatment}

Although first-step therapy in glucose control is weight loss and exercise, pharmacologic antidiabetic treatment may be necessary if lifestyle changes prove inadequate [26]. The UKPDS established that in subjects receiving intensive therapy with either sulfonylurea or insulin, the microvascular complication rate was reduced by $25 \%$ compared with persons who received conventional dietary therapy [28]. Furthermore, the use of hypoglycemic agents in combination often results in blood glucose reductions that are significantly greater than those that can be obtained with maximal doses of any single drug [29]. In Augsburg combined therapy using several antidiabetic agents became increasingly common between 1984/85 (S1) and 1999/2001 (S4). Also, the use of insulin increased during this period (Fig. 2). On the other hand, during the study period the percentage of men and women receiving no pharmacologic antidiabetic therapy decreased continuously. These efforts are consistent with recommendations to intensify glucose control in persons with type 2 diabetes [28, 29].

\section{Impact of diabetes on CVD morbidity}

People with diabetes are two to four times more likely to develop CVD as people without diabetes [3]. In one population-based study, the 7-year incidence of first myocardial infarction or death for patients with diabetes was $20 \%$ but was only $3.5 \%$ for nondiabetic patients. History of MI increased the rate of recurrent MI or CVD death events for both groups (18.8\% in non-diabetic persons and $45 \%$ in those with diabetes). Thus, patients with diabetes but without previous MI carry about the same level of risk for subsequent acute coronary events as non-diabetic patients with previous MI [4]. A similar risk estimate was found in the MONICA Augsburg population [30, 31]. Diabetes also worsens early and late outcomes in acute coronary syndromes. Results from the population-based Augsburg myocardial infarction registry showed that the mortality rate within 28 days after MI was $12.6 \%$ in diabetic patients and $7.3 \%$ in non-diabetic patients 
$(p=0.001)$. Furthermore, mortality in diabetic patients over 5 years after MI was increased by $64 \%$ compared with nondiabetic patients [30].

Recent data from the MONICA/KORA Augsburg myocardial infarction registry suggest an impressive increase of the proportion of AMI patients with a positive history of diabetes mellitus (Fig. 3) between 1985/87 and 2000/02. The age-standardized AMI attack rate per 100,000 population decreased from 534 $(95 \%$ CI $510 ; 557)$ to $396(95 \%$ CI $379 ; 412)$ in non-diabetic men aged 25 to 74 years and from $152(95 \%$ CI $141 ; 162)$ to $122(95 \%$ CI $114 ; 131)$ in non-diabetic women of the same age. On the contrary, among 25 to 74 year old persons with diabetes the risk of an AMI did not decrease during the study period. The age-standardized AMI attack rate per 100,000 population was 115 (95\% CI $104 ; 126)$ in diabetic men in 1985/87 and 135 (95\% CI 125; 144 ) in $2000 / 02$, respectively. The corresponding values for diabetic women were 61 (95\% CI 55; 68) and 51 (95\% CI 45; 57) per 100,000 population, respectively. These findings underline the challenge that in particular persons with diabetes should receive intensive preventive interventions proven to reduce cardiovascular risk.

\section{Conclusions}

Type 2 diabetes is a global public health problem that is common, growing, serious and costly. Although the prevalence of known diabetes mellitus was stable over a time period of 17 years, in the future an increase in diabetes prevalence could be expected in Southern Germany. Because of a high percentage of undiagnosed type 2 diabetes in the German population major efforts to screen individuals at risk for the development of diabetes are important. Early diagnosis is of particular relevance because data indicated that CVD complications of diabetes become manifest in persons many years before the diagnosis of clinical type 2 diabetes [24]. Persons with diabetes are at a greatly increased risk for morbidity and mortality from myocardial infarction, stroke, congestive heart failure, renal failure, and other cardiovascular diseases [32]. Several studies demonstrated that improved glycemic control and aggressive treatment of hypertension and hyperlipidemia can significantly reduce the risk for macrovascular events in diabetic patients, with or without prior cardiovascular complications [26, 27, 33]. Data from the MONICA/KORA Augsburg studies showed that the risk factor profile in persons with diabetes mellitus is still far from optimal with the

Table 1 Prevalence (\%) of lifestyle factors ${ }^{2}$ and cardiovascular risk factors 6 in participants with type 2 diabetes aged 25 to 64 and 65 to 74 years, respectively, in the four population based MONICA/KORA surveys $\$ 1$ - S4

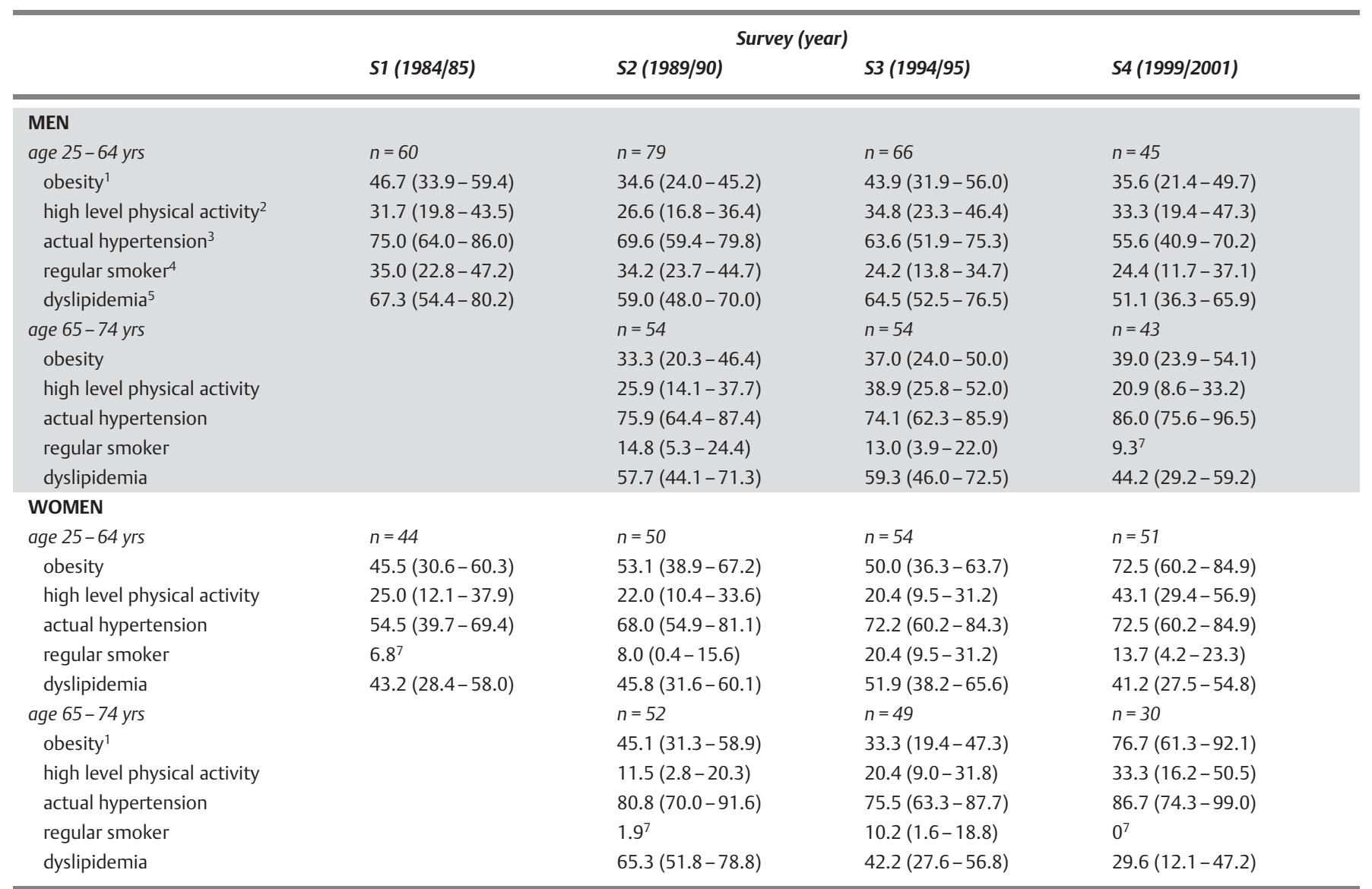

${ }^{1}$ obesity: BMI $\geq 30 \mathrm{~kg} / \mathrm{m}^{2} ;{ }^{2}$ high level physical activity: participating in sports in summer and in winter and for more than one hour per week in at least one season; 3 actual hypertension: persons being aware of having hypertension, taking antihypertensive medication, and/or having blood pressure values $\geq 140 / 90$ mm Hg; 4 regular smoker: smoking of at least one cigarette per day; ${ }^{5}$ dyslipidemia: total cholesterol to high density cholesterol (HDL)-ratio $\geq 5.0 ;{ }^{6}$ There were several missings for the single risk factor measurements. ${ }^{7}$ Due to low prevalences no confidence intervals could be calculated. 
consequence, that the proportion of diabetic patients among men and women suffering from an acute coronary event remained almost stable since 1985 . Therefore, it should become an important public health priority to develop strategies for an uncompromising, multi-component attack on all modifiable risk factors for CVD, including glucose control, in persons with diabetes mellitus.

\section{Future planning}

The data of S1-S4 as well as data from the MONICA/KORA myocardial infarction registry in combination with updated followup information on all study participants allows us to investigate trends, cross-sectional and prospective questions in the field of type 2 diabetes epidemiology. In the future we will focus on risk factors and possible sex differences for incident type 2 diabetes with particular attention on environmental factors. In addition, the MONICA/KORA Augsburg studies provide the possibility to investigate the genetic basis of type 2 diabetes as well as geneenvironment interactions responsible for the development of the disease. Furthermore, the MONICA/KORA Augsburg myocardial infarction registry will continue to examine changes in medical care, as well as in survival and 28-day case fatality after MI among the diabetic and non-diabetic population.

\section{Acknowledgement}

The KORA research platform and the MONICA Augsburg studies were initiated and financed by the GSF - National Research Center for Environment and Health, which is funded by the German Federal Ministry of Education, Science, Research and Technology (BMBF-FKZ: 01ER9701/4; survey 1984/85: BMFT 07064 279) and by the State of Bavaria. We thank all members of the GSF Institute of Epidemiology who were involved in the planning and conduct of the surveys. Furthermore, we thank the company Socialdata (Munich), for the organization and realization of the survey 1984/85 and the company B. Schwertner (Augsburg), for the organization of the surveys 1989/90, 1994/95 and of the followup questionnaire in 1998. We also thank the MONICA/KORA myocardial infarction registry team (Augsburg), the team of the KORA study center (Augsburg) and Prof. U. Keil (University of Münster, Germany) who was the principal investigator of the MONICA Augsburg study. Finally, we express our appreciation to all study participants.

The investigations on diabetes in MONICA/KORA have been supported by GSF, DDZ-Deutsches Diabeteszentrum, BMBF - Federal Ministry of Education and Research (FKZ 01ER 9502/0, 01GS0423, and NGFN) and DFG - Deutsche Forschungsgemeinschaft (TH 784/2-1, Wi 621/9-1).

The article refers specifically to the following contribution of this special issue of Das Gesundheitswesen: [12,13, 21].
References

${ }^{1}$ Resnick HE, Shorr RI, Kuller L et al. Prevalence and clinical implications of American Diabetes Association-defined diabetes and other categories of glucose dysregulation in older adults. J Clin Epidemiol 2001; 54: 869-876

${ }^{2}$ Klein R. Hyperglycemia and microvascular and macrovascular disease in diabetes. Diabetes Care 1995; 18: 258 - 268

${ }^{3}$ Feskens EJ, Kromhout D. Glucose tolerance and the risk of cardiovascular disease: the Zutphen Study. J Clin Epidemiol 1992; 45: 1327 1334

${ }^{4}$ Haffner SM, Lehto S, Ronnemaa T et al. Mortality from coronary heart disease in subjects with type 2 diabetes and in nondiabetic subjects with and without prior myocardial infarction. N Engl J Med 1998; 339: $229-234$

${ }^{5}$ Newman AB, Siscovick DS, Manolio TA et al. Ankle-arm index as a marker of atherosclerosis in the Cardiovascular Health Study. Circulation 1993; 88: 837-845

${ }^{6}$ Fabris F, Zanocchi M, Bo M et al. Carotid plaque, aging, and risk factors. Stroke 1994; 25: $1133-1140$

${ }^{7} \mathrm{Gu}$ K, Cowie CC, Harris MI. Diabetes and decline in heart disease mortality in U.S. adults. JAMA 1999; 281: $1291-1297$

${ }^{8}$ Illig T, Bongardt F, Schöpfer A et al. Kooperative Gesundheitsforschung im Raum Augsburg/Cooperative Research in the Region of Augsburg. Significant association of the interleukin-6 gene polymorphisms C-174G and A-598G with type 2 diabetes. J Clin Endocrinol Metab 2004; 89: 5053-5058

${ }^{9}$ King H, Aubert RE, Herman WH. Global burden of diabetes $1995-$ 2025. Prevalence, numerical estimates, and projections. Diabetes Care 1998; 21: $1414-1431$

${ }^{10}$ Keil U, Liese AD, Hense HW et al. Classical risk factors and their impact on incident non-fatal and fatal myocardial infarction and all-cause mortality in southern Germany. Results from the MONICA Augsburg cohort study 1984 - 1992. Eur Heart J 1998; 19: 1197-1207

${ }^{11}$ Hense HW, Filipiak B, Döring A et al. Ten-year trends of cardiovascular risk factors in the MONICA Augsburg Region in Southern Germany. Results from the 1984/85, 1989/90, and 1994/95 surveys. CVD Prevention 1998; 1 : $318-327$

12 Holle R, Happich M, Löwel H et al. KORA - A research platform for population based health research. Gesundheitswesen 2005; 67 S1: S19S25

${ }^{13}$ Löwel H, Meisinger C, Heier M et al. The population-based Acute Myocardial Infarction (AMI) Registry of the MONICA/KORA study region of Augsburg. Gesundheitswesen 2005; 67 S1: S31 -S37

${ }^{14}$ Diamond J. The double puzzle of diabetes. Nature 2003; 423: 599602

${ }^{15}$ Katsilambros N, Aliferis K, Darviri C et al. Evidence for an increase in the prevalence of known diabetes in a sample of an urban population in Greece. Diabet Med 1993; 10: 87-90

${ }^{16}$ Neil HA, Gatling W, Mather HM et al. The Oxford Community Diabetes Study: evidence for an increase in the prevalence of known diabetes in Great Britain. Diabet Med 1987; 4: 539-543

${ }^{17}$ Laakso M, Reunanen A, Klaukka T et al. Changes in the prevalence and incidence of diabetes mellitus in Finnish adults, 1970-1987. Am J Epidemiol 1991; 133: 850-857

${ }^{18}$ Meisinger C, Heier M, Doering A et al. Prevalence of known diabetes and antidiabetic therapy between 1984/85 and 1999/2001 in Southern Germany. Diabetes Care 2004; 27: 2985-2987

19 Thefeld W. Prävalenz des Diabetes mellitus in der erwachsenen Bevölkerung Deutschlands. Gesundheitswesen 1999; 61: 85 -S89

20 Rathmann W, Haastert B, Icks A et al. High prevalence of undiagnosed diabetes mellitus in Southern Germany: Target populations for efficient screening. The KORA survey 2000. Diabetologia 2003; 46: $182-$ 189

${ }^{21}$ Rathmann W, Haastert B, Icks A et al. The diabetes epidemic in the elderly population in Western Europe: data from population-based studies. Gesundheitswesen 2005; 67 S1: S110-S114

22 Tuomilehto J, Lindström J, Eriksson JG et al. Prevention of type 2 diabetes mellitus by changes in lifestyle among subjects with impaired glucose tolerance. N Engl J Med 2001; 344: $1343-1350$

${ }^{23}$ Knowler WC, Barrett-Connor E, Fowler SE et al. Reduction in the incidence of type 2 diabetes with lifestyle intervention or metformin. N Engl J Med 2002; 346: $393-403$ 
${ }^{24}$ Haffner SM, Stern MP, Hazuda HP et al. Cardiovascular risk factors in confirmed prediabetic individuals. Does the clock for coronary heart disease start ticking before onset of clinical diabetes? JAMA 1990; 263: $2893-2898$

${ }^{25}$ Meisinger C, Thorand B, Schneider A et al. Sex differences in risk factors for incident type 2 diabetes mellitus. The MONICA Augsburg Cohort Study. Arch Intern Med 2002; 162: 82 - 89

${ }^{26}$ Pearson TA, Blair SN, Daniels SR et al. AHA Guidelines for primary prevention of cardiovascular disease and stroke: 2002 update. Circulation 2002; 106: $388-391$

${ }^{27}$ De Backer G, Ambrosioni E, Borch-Johnsen K et al. European guidelines on cardiovascular disease prevention in clinical practice. Eur Heart J 2003; 24: 1601 - 1610

28 UK Prospective Diabetes Study Group. Intensive blood glucose control with sulfonylureas or insulin compared with conventional treatment and risk of complications in patients with type 2 diabetes (UKPDS 33). Lancet 1998; 352: 837-853

${ }^{29}$ Riddle M. Combining sulfonylureas and other oral agents. Am J Med 2000; 108: $15-22$

${ }^{30}$ Löwel H, Koenig W, Engel S et al. The impact of diabetes mellitus on survival after myocardial infarction: can it be modified by drug treatment? Results of a population-based myocardial infarction register follow-up study. Diabetologia 2000; 43: 218-226

${ }^{31}$ Löwel H, Stieber J, Koenig W et al. The diabetes-related risk of acute myocardial infarction in a southern German population: Results of the MONICA-Augsburg-studies 1985-1994. Diab Stoffw 1999; 8: $11-21$

32 Winer N, Sowers JR. Epidemiology of diabetes. J Clin Pharmacol 2004; 44: 397-405

${ }^{33}$ Hansson L, Zanchetti A, Carruthers SG et al. Effects of intensive bloodpressure lowering and low-dose aspirin in patients with hypertension: principal results of the Hypertension Optimal Treatment (HOT) randomised trial. HOT Study Group. Lancet 1998; 351: 1755-1762 